\title{
On the long-term variability of temperature trends and changes in surface air temperature in Kolkata Weather Observatory, West Bengal, India
}

\author{
Ansar Khan \\ khanansargeo@gmail.com \\ Soumendu Chatterjee \\ Department of Geography, Presidency University, Kolkata 700073, India \\ Dipak Bisai \\ Department of Geography, Egra S.S.B College, Egra 721429, India
}

Department of Geography and Environment Management, Vidyasagar University, Midnapore 721102, India, e-mail:

\begin{abstract}
The impact of climate change on annual air temperature has received a great deal of attention from climatologists worldwide. Many studies have been conducted to illustrate that changes in temperature are becoming evident on a global scale. Air temperature, one of the most important components of climate parameters, has been widely measured as a starting point towards the apprehension of climate change and variability. The main objective of this study is to analyse the temporal variability of mean monthly temperature for the period of 1941 to 2010 (70 years). To detect the magnitude of trend in mean monthly temperature time series, we have used non-parametric test methods such as The Mann-Kendall test, often combined with the Theil-Sen's robust estimate of linear trend. Whatever test is used, the user should understand the underlying assumptions of both the technique used to generate the estimates of a trend and the statistical methods used for testing. The results of this analysis reveal that four months - January, February, March and December - indicate a decreasing trend in average temperature, while the remaining eight months have an increasing trend. The magnitude of Mann-Kendall trend statistic Zc for this declining temperature and the magnitude of slope for the months of January, February and December are confirmed at the high significance levels of $\alpha=0.001,0.01$ and 0.1 respectively. Though, the overall trend is positive for monthly as well as seasonally efficient time series.
\end{abstract}

Keywords: temperature, trend analysis, Mann-Kendall test, Sen's slope estimator, Kolkata

Submitted 1 October 2014, revised 4 November 2014, accepted 9 September 2015

\section{Introduction}

The detection, estimation and prediction of trends and associated statistical and physical significance are important aspects of climate research. Given a time series of temperatures, the trend is the rate at which temperature changes over a time period. The trend may be linear or non-linear (Adgeret al. 2007). However, generally, it is synonymous with the linear slope of the line fit to the time series. Examination of change in lower atmospheric temperature trends is one of the most critical studies in determining the overall impact of climate change. Air temperature is the principle element of a weather system; therefore examination of its behaviour is important for understanding climate variability because it is highly variable spatially and temporally at different scales of geography - local, regional and global. The variability of air temperature could lead to longer dry spells and a higher risk of flood in different regional scales. The Fourth Assessment report of the Intergovernmental Panel on Climate Change (IPCC 2007) shows that the global mean surface air temperature increased by $0.74^{\circ} \mathrm{C}$, while the global mean sea surface temperature (SST) increased by $0.67^{\circ} \mathrm{C}$ over the last century. In the regional context, the diurnal asymmetry of temperature trends indicating a warming over the India is explained to have been contributed solely by maximum temperature (Kothawale, Rupa Kumar 2005). However, as the results from analysis of mean minimum temperatures do not suggest a statistically significant increase, it has been concluded that most of the increases in mean surface air temperature over India are due to the increase in daytime temperature. There has been a fall of $0.38^{\circ}$ per century in the north Indian average temperature, with a contrasting increase of $0.42^{\circ} \mathrm{C}$ per century, as depicted by the average temperature of India during the second half of the $20^{\text {th }}$ century (Aroraet al. 2005). The variation and 
magnitude of warming is higher in the post-monsoon and winter seasons. No recent literature on monsoon temperature analysis has shown a significant trend in any part of India, except for a significant negative trend over northwest India. Mean annual temperature was found to be increasing over the west coast, the interior peninsular, northcentral and north-east regions of India, along with the whole of India during the period from 1901 to 1982 (Hinganeet al. 1985). Adecadal study of air temperature for trend analysis over India indicated that the diurnal asymmetry of temperature trends over India is quite different from that over many other parts of the globe (Srivastava et al. 1992). The long-term warming trend, indicating continual warming since the mid-1970s, has been conclusively associated with the predominant global climate forcing, influenced by manmade greenhouse gases, which began to grow substantially from the early $20^{\text {th }}$ century onwards (IPCC 2007). Therefore, the regional temperature trend may have been influenced by these causes. The increasing trend in the number of short spells of heavy rain and decreasing trend in the occurrence of long spells of rain are very often present in India (Dash et al. 2007).

As was found by Pramanik and Jagannathan (1954), changes in temperature and their association with climate change are very important for future climate projection. They studies secular trends in the annual mean maximum and minimum temperatures over India and concluded that there is no general tendency for an increase in these temperatures. Jagannathan and Parathasarathy (1973) analysed the time series of mean annual temperatures of Kolkata, Mumbai, Bangalore and Allahabad, and a decreasing trend at Cochin. The review of climate change over the previous 80 years indicates a slight warming trend in dry-bulb temperature, while rainfall showed no trend. Sarker and Thapliyal (1988) found that over a major part of the country maximum temperatures show much larger increasing trends than minimum temperatures. A decreasing trend in temperature over most of the northern parts of the country (north of $23^{\circ} \mathrm{N}$ ), coupled with an increasing trend over southern parts (south of $23^{\circ} \mathrm{S}$ ) and an overall slightly increasing trend of the order of $0.35^{\circ} \mathrm{C}$ was observed during the last 100 years. Pant and Rupa Kumar (1997) analysed the data for 18811997 and showed that there is a significant warming trend at the rate of $0.57^{\circ} \mathrm{C}$ per hundred years. The magnitude of warming is higher in the post-monsoon and winter seasons. No significant trends were noted for rainfall on either an annual or a seasonal basis (Sinha Ray, De 2003). The main objective of this study is to find out the monotonic trend and fluctuations (month-wise) of mean monthly temperature at Kolkata observatory with the use of Mann-Kendall trend test and Sen's Slope Estimator.

\section{Study area}

Kolkata $\left(22^{\circ} 35^{\prime} \mathrm{N}\right.$ and $\left.88^{\circ} 30^{\prime} \mathrm{E}\right)$ is the capital city and largest urban agglomeration of the state of West Bengal. In the British colonial period it was once the capital of India. As such, it has witnessed a rapid growth of population over many decades and, according to the 2011 census, it is the $3^{\text {rd }}$ most populated metropolitan city in India. The River Hoogly flows along the western margin of this metropolitan area. The area under urban cover, and also the population, has increased throughout its long history, from the early colonial period onwards. Kolkata is subject to a tropical wet-and-dry climate, designated as "Aw" type under the Koppen climate classification system. The annual mean temperature is $26.8^{\circ} \mathrm{C}\left(80.2^{\circ} \mathrm{F}\right)$; the monthly mean temperature ranges between $19^{\circ} \mathrm{C}$ to $30^{\circ} \mathrm{C}\left(66^{\circ} \mathrm{F}\right.$ to $86^{\circ} \mathrm{F}$ ). During dry spells, maximum temperatures often exceed $40^{\circ} \mathrm{C}\left(104^{\circ} \mathrm{F}\right)$ - in the months of May and June. The winter spell is very short: it lasts for only about two months, with seasonal low temperature ranging between $9^{\circ} \mathrm{C}$ and $11^{\circ} \mathrm{C}\left(48^{\circ} \mathrm{F}\right.$ to $\left.52^{\circ} \mathrm{F}\right)$ in the months of December and January. May is the hottest month, with daily temperature ranging from $27^{\circ} \mathrm{C}$ to $37^{\circ} \mathrm{C}\left(81^{\circ} \mathrm{F}\right.$ to $\left.99^{\circ} \mathrm{F}\right)$; January, the coldest month, has temperatures varying from $12^{\circ} \mathrm{C}$ to $23^{\circ} \mathrm{C}\left(54^{\circ} \mathrm{F}\right.$ to $\left.73^{\circ} \mathrm{F}\right)$, according to the recent past climatological records. The highest recorded temperature is $43.9^{\circ} \mathrm{C}\left(111.0^{\circ} \mathrm{F}\right)$, and the lowest is $5^{\circ} \mathrm{C}\left(41^{\circ} \mathrm{F}\right)$, as measured at the Alipore Weather Observation Station. During April-June, the city eventually experiences heavy rains or dusty squalls followed by thunderstorms or hailstorms, bringing cooling relief from the consistent high temperature and humidity in this region.

\section{Climatological data and methods}

Trend analysis of a time series consists of determining the magnitude of a trend and finding statistical significance of a trend. We have used for analysis monthly mean minimum and maximum temperature records collected from the Indian Meteorological Department (Kolkata, Alipore). The considered data period ranges from 1941 to 2010 (70 years) and the series are continuous, without any missing data. Those data were statistically processed and then reduced to monthly values for further analysis.

\subsection{Monotonic changes through Standard Normal Ho- mogeneity Test (SNHT)}

A test for the detection of linear trends of arbitrary length in normally distributed time series was developed. With this test it is possible to detect and estimate gradual 
changes of the mean value in a candidate series compared with a homogeneous reference series. The test is intended for studies of artificial relative trends in climatological time series, e.g. an increasing urban heat island effect. The basic structure of the new test is similar to that of a widely used test for abrupt changes, the standard normal homogeneity test. The test for abrupt changes has been found to remain unaltered after an important generalization (Alexandersson, Moberg 1997). SNHT is a parametric test using neighboring station(s) as a reference to identify nonhomogeneities in the time series of the station being tested (candidate station). It is used to detect abrupt or linearly developing differences between the candidate and the reference station(s). Hawkins (1977) presented a formulation of a testing method that was subsequently developed into SNHT and applied to climatological series by Alexandersson $(1984,1986)$. The SNHT is related to a curve fitting technique using the least squares principle (Alexandersson, Moberg 1997). The basic assumption behind SNHT is that the difference, $Q$ between e.g. temperature at the candidate station and a neighboring reference station remains fairly constant in time. This requires a sufficient correlation between the test and reference stations. Anonhomogeneity will be revealed as a systematic change in this difference, $Q$, which is defined in this analysis, where techniques for constructing reference series are also discussed.

\subsection{Building reference series}

In this time series, $y$ denotes our candidate series and $y_{i}$ denotes a specific value (e.g. annual accumulated temperature) at year (or other time unit) $i$. Furthermore, $x_{j}$ denotes one of the surrounding reference sites (the $j^{\text {th }}$ of a total of $k$ ), and $x_{j i}$ a specific value from that site. To detect relative non-homogeneities, researchers adopted the following difference (by tradition used in temperature studies):

$$
Q_{i}=Y_{i}-\left\{\sum_{j=1}^{k} \rho_{j}^{2}\left[X_{j i}-\bar{X}_{j}+\bar{Y}\right] / \sum_{j=1}^{k} \rho_{j}^{2}\right\}
$$

the denominator in the above equation (both expressed within brackets) reference values as they are intended to be reasonable and stable estimates for the candidate site using a set of neighboring reference stations. In this equation $\rho_{j}$ denotes the correlation coefficient between the candidate site and a surrounding station. This coefficient must be positive. The normalizing is important because it allows us to use different sets of neighboring stations at different years, including shorter and non-complete records, when we calculate reference values. The norma- lizing also causes the $Q$-values to fluctuate around 1 . It is necessary that the mean values of $y$ and $x_{j}$ are calculated for one common time period for all $j=1 \ldots k$. Otherwise the size of non-homogeneities may be underestimated or missed by the test. The correlation coefficients $\rho_{j}$ need not, for algebraic reasons, be estimated from the same common time period, but it seems reasonable to use one common period for all stations.

The standard normal homogeneity tests are applied to the standardized series:

$$
Z_{i}=\frac{\left(Q_{i}-\bar{Q}\right)}{\sigma_{Q}}
$$

Alexandersson and Moberg (1997) used ( $n-1)$ in computing standard deviations $\sigma_{Q}$. This is important to mention because it influences the test statistic and the critical levels. Where $\bar{Q}$ is the sample mean value and $\sigma_{Q}$ the sample standard deviation of the difference $Q_{i}$ at time step $i$ (denoted in many climatological applications as one year). In the following discussion, "year" will be used instead of "time step" or "time unit", although the time step is by no means restricted to one year.

\subsection{Single shift of the mean level, two variants}

A single shift of the mean level at the candidate site $y$ can be expressed formally with a null hypothesis $\left(H_{0}\right)$ or an alternative hypothesis $\left(H_{1}\right)$ as:

$$
\begin{gathered}
H_{0}: Z_{i} \in N(0,1) \quad i \in\{1 \ldots n\} \\
H_{1}:\left\{\begin{array}{l}
Z_{i} \in N\left(\mu_{1}, \sigma\right) \quad i=\in\{1 \ldots n\} \\
Z_{i} \in N\left(\mu_{1}, \sigma\right) \quad i=\in\{a+1 \ldots \mathrm{n}\}
\end{array}\right\}
\end{gathered}
$$

where $\mu_{1}$ is the mean value during the first a years, $\mu_{2}$ is the mean value during the last $(n-a)$ years, and $\sigma$ is the sample standard deviation.

Alexandersson (1986) and Alexandersson, Moberg (1997) show how the test quantity, $T$, which separates $H_{1}$ from $H_{0}$, is derived. The interpretation of $T$ is that a high value at year $a$ suggests that $\mu_{1}$ and $\mu_{2}$ depart significantly from zero, making $H_{1}$ likely. The maximum value of $T$, denoted $T_{\max }$, and is:

$$
T_{\max }^{s}=\max _{1 \leq a \leq n-1}\left\{T_{a}^{s}\right\}=\max _{1 \leq a \leq n-1}\left\{a \bar{z}_{1}^{2}+(n-a) \bar{z}_{2}^{2}\right\}
$$

where $\bar{z}_{1}$ and $\bar{z}_{2}$ are the mean values before and after the shift. The corresponding value of $a$ is the most probable break point, i.e. the last year at the old level. The null hypothesis can be rejected, if $T_{\max }$ is above the selected sig- 
nificance level, which depends on the length of the series. Alexandersson, Moberg (1997) give critical $T$ values for $10 \%, 5 \%$ and $2.5 \%$ levels, $T_{90}, T_{95}$, and $T_{97.5}$ respectively. According to Hawkins (1977) there is an increased probability of high $T$ values near the ends of series where a few low or high values of $Z_{i}$ make $T_{a}^{s}$ large.

\subsection{Adjustments of series}

SNHT provides an estimate of the size of the detected discontinuity that can be used to adjust an inhomogeneous series. In the single shift test, the two levels of the differences derived from $q_{1}$ and $q_{2}$, are:

$$
\begin{aligned}
& \bar{q}_{1}=\sigma Q^{\bar{z}_{1}}+\bar{Q} \\
& \bar{q}_{2}=\sigma Q^{\bar{z}_{2}}+\bar{Q}
\end{aligned}
$$

The adjustment for years from 1 to $a$ is $\bar{q}_{2} / \bar{q}_{1}$ for the difference. After the adjustments have been applied, the data are homogenized to the present measuring situation, provided that the series contain only one homogeneity break. Double shift adjustments are calculated in a similar manner as for the single shift. Trend adjustments must be calculated with $\mu_{1}$ and $\mu_{2}$, and then applied in time series.

One possible way to handle a change in both the mean level and standard deviation has been described (Alexandersson et al. 1995). Firstly, linear regressions between the candidate and the reference series are formed, both before and after the homogeneity break. Secondly, the change of slope of the regression line is used as an amplification/ damping factor in the adjustment procedure. If reference values are denoted with $R$, linear regression of the candidate value $Y$ becomes:

$$
Y=\alpha R+\beta
$$

where $\alpha$ is the slope and $\beta$ is the $y$ axis intercept. The regressions are calculated before and after the break, and denoted 1 and 2, respectively. The adjusted value at the candidate station, $Y^{a}{ }_{i}$ can be calculated as:

$$
Y_{i}^{a}=\bar{Y}_{1}+\Delta Y+\left(a_{2} / a_{1}\right)\left(Y_{i}-\bar{Y}\right)
$$

here $\Delta Y$ is the change of the mean level. The last term is the amplification/damping factor, which is the ratio of slopes times' anomaly.

The use of reference series in the calculation of adjustments introduces a regionalization effect into the data. The adjustment of series to represent homogeneous conditions at a particular site can be difficult. It is possible that procedures using other climatic elements (e.g. temperature with wind, albedo, stability, etc.) might help, but this is not usually done. In any case, the original data must always be preserved because new and better approaches to homogeneity adjustments may be developed.

\subsection{Test of serial dependence-independence effect through serial correlation}

One of the main problems in testing and interpreting trends is the effect of serial dependence. The presence of positive or negative autocorrelation affects the detection of a trend in a series (Hamed, Rao 1998; Yue et al. 2003). With a positive autocorrelation (persistence) in the time series, the Mann-Kendall test would detect a significant trend in the time series when there may be actually none, or vice versa. To remove serial correlation from the series, von Storch and Navarra (1995) suggested prewhitening the series before applying the Mann-Kendall test. This study incorporates this suggestion in both the MannKendall test and in Sen's slope estimator. Therefore, all the temperature series are first tested for serial correlation using lag-1 autocorrelation coefficient $\left(r_{1}\right)$ given in the equation at $5 \%$ significance level for a two-tailed test. Possible statistically significant trends in sample data $x_{1}, x_{2} \ldots$ $x_{n}$ are examined using the following procedures:

(1) Compute the lag-1 serial correlation coefficient $r_{1}$. The lag-1 serial correlation coefficient of sample data $x_{i}$ can be computed by (Kendall, Stuart 1968; Salas et al. 1980) and:

$$
E\left(x_{i}\right)=\frac{1}{n} \sum_{i=1}^{n} x_{i}
$$

where $E\left(x_{i}\right)$ is the mean of sample data and $n$ is the sample size.

(2) If the calculated $r_{1}$ is not significant at the $5 \%$ level, then the Mann-Kendall test and Sen's slope estimator are applied to the original values of the time series.

$$
r_{1}=\frac{\frac{1}{n-1} \sum_{i=1}^{n-1}\left(x_{i}-E(x)\right) \cdot\left(x_{i+1}-E\left(x_{i}\right)\right)}{\frac{1}{n} \sum_{i=1}^{n}\left(x_{i}-E(x)\right)^{2}}
$$

(3) If the calculated $r_{1}$ is significant, prior to the application of the Mann-Kendall test and Sen's slope estimator, then the 'pre-whitened' time series may be obtained as $\left(x_{2}-r_{1} x_{1}, x_{3}-r_{1} x_{2} \ldots x_{n}-r_{1} x_{n-1}\right)$.

The critical value of $r_{1}$ for a given significance level depends on whether the test is one-tailed or two-tailed. For the one-tailed hypothesis, the alternative hypothesis is usually that the true $r_{1}$ is greater than zero, while for the two-tailed test, the alternative hypothesis is that the true $r_{1}$ is different from zero, with no specification of whether it is positive or negative. The $r_{1}$ is tested against the null hypothesis using the Anderson (1942) limit for the two tailed test. 


$$
r_{1}(95 \%)=\frac{-1 \pm 1.96 \sqrt{(n-2)}}{n-1}
$$

where $n$ is the sample size.

If the $r_{1}$ value falls within the confidence interval given above, the data are assumed to be serially independent. If not, the sample data are considered to be significantly serially correlated.

\section{Detection of nature and slope of trends 4.1. Mann-Kendall (MK) test}

The Mann-Kendall test is a rank based nonparametric test and has recently been used by several researchers to detect trends in rainfall data (de la Casa, Nasello 2010; Shifteh et al. 2012; Tabari et al. 2011). It is based on the test statics $S$, defined as:

$$
S=\sum_{i=1}^{n-1} \sum_{j=i+1}^{n} \operatorname{sgn}\left(x_{j}-x_{i}\right)
$$

where, $x_{1}, x_{2} \ldots x_{n}$ represent $n$ data points, and where $x_{j}$ represents the data point at time $j$.

A very high positive value of $S$ is an indicator of an increasing trend, and a very low negative value indicates a decreasing trend.

$$
\operatorname{sgn}\left(x_{j}-x_{i}\right)\left\{\begin{array}{l}
f o r\left(\mathrm{x}_{j}-x_{i}\right)>1 \\
\operatorname{for}\left(\mathrm{x}_{j}-x_{i}\right)=0 \\
\operatorname{for}\left(\mathrm{x}_{j}-x_{i}\right)<1
\end{array}\right\}
$$

It has been documented that when $n \geq 10$, the statistic $S$ is approximately normally distributed with the mean:

$$
E(S)=0
$$

and its variance is:

$$
\operatorname{Var}(S)=\frac{n(n-1)(2 n+5)-\sum_{i=1}^{m} t_{i}\left(t_{i}-1\right)\left(2 t_{i}+5\right)}{18}
$$

where $n$ is the number of data points, $m$ is the number of tied groups (a tied group is a set of sample data having the same value), and $t_{i}$ is the number of data points in the $i^{\text {th }}$ group. The standardized test statistic $Z$ is computed as follows:

$$
Z=\left\{\begin{array}{l}
\frac{S-1}{\sqrt{\operatorname{Var}(S)}} \\
0 \\
\frac{S+1}{\sqrt{\operatorname{Var}(S)}}
\end{array}\right\}\left\{\begin{array}{l}
\text { if } S>0 \\
\text { If } S=0 \\
\text { if } S<0
\end{array}\right\}
$$

The null hypothesis $H_{0}$, meaning that no significant trend is present, is accepted if the test statistic $Z$ is not statistically significant, i.e. $-Z_{\alpha / 2}<Z<Z_{\alpha / 2}$, where $Z_{\alpha / 2}$ is the standard normal deviate.

\subsection{Theil-Sen's estimator}

The slope of $n$ pairs of data points was estimated using the Theil-Sen's estimator (Sen 1968), which is given by the following relation:

$$
T_{i}=\frac{x_{j}-x_{i}}{j-i}
$$

$x_{j}$ and $x_{i}$ presents as data values at time $j$ and $i(j>i)$ respectively. The median of the $N$ values of $T_{i}$ is considered as Sen's slope estimator, which is calculated by the formula:

$$
Q_{i}=\left\{\begin{array}{l}
\frac{T_{N+1}}{2} \\
\frac{1}{2}\left(T_{\frac{N}{2}}+T_{\frac{N+2}{2}}\right)
\end{array}\right)\left\{\begin{array}{l}
N=\text { odd } \\
N=\text { even }
\end{array}\right\}
$$

A positive value of $Q_{i}$ indicates an increasing trend and a negative value of $Q_{i}$ indicates a decreasing trend in a time series (Xu et al. 2010). The $Q_{i}$ reflects data trend reflection, while its value indicates the steepness of the trend. To determine whether the median slope is statistically different than zero, one should obtain the confidence interval of $Q_{i}$ at specific probability.

The confidence interval about the time slope (Hollander, Wolfe 1973) can be computed as follows:

$$
C_{\alpha}=Z_{1-\alpha / 2 \sqrt{\operatorname{Var}(S)}}
$$

In this study, the confidence interval was computed at two significance levels $(\alpha=0.01, \alpha=0.05)$. Then, $M_{1}=\frac{N-C_{a}}{2}$ and $M_{2}=\frac{N-C_{a}}{2}$ were computed. The lower and upper limits of the confidence interval, $Q_{\min }$ and $Q_{\max }$, were the $M_{1}^{\text {th }}$ largest and the $\left(M_{2}+1\right)^{\text {th }}$ largest of the $N$ ordered slope estimates (Gilbert 1987). The slope $Q_{i}$ was statistically different than zero if the two limits $\left(Q_{\min }, Q_{\max }\right)$ had a similar sign. Sen's slope estimator has been widely used in hydro-meteorological time series.

\section{Results and Discussion}

In the climatic seasons, researchers observe different tendencies of changes in air temperature. The trend in mean monthly temperature time series for Kolkata observatory has been analysed using the Mann-Kendall test and Sen's slope estimator. Figure 1 shows the mean annual temperature variation, where the maximum mean annual temperature was recorded in 1961, and the minimum in 1985. Mean temperature for each of the months when averaged over the 70 years reveals that the mean monthly temperature for January is the lowest $\left(21.69^{\circ} \mathrm{C}\right)$ while for November and February it is $24.79^{\circ} \mathrm{C}$ and $25.00^{\circ} \mathrm{C}$ respec- 
tively. On the other hand, May has the highest average temperature - of $31.18^{\circ}$ - followed by April $\left(30.88^{\circ} \mathrm{C}\right)$ and June $\left(30.82^{\circ} \mathrm{C}\right)$.

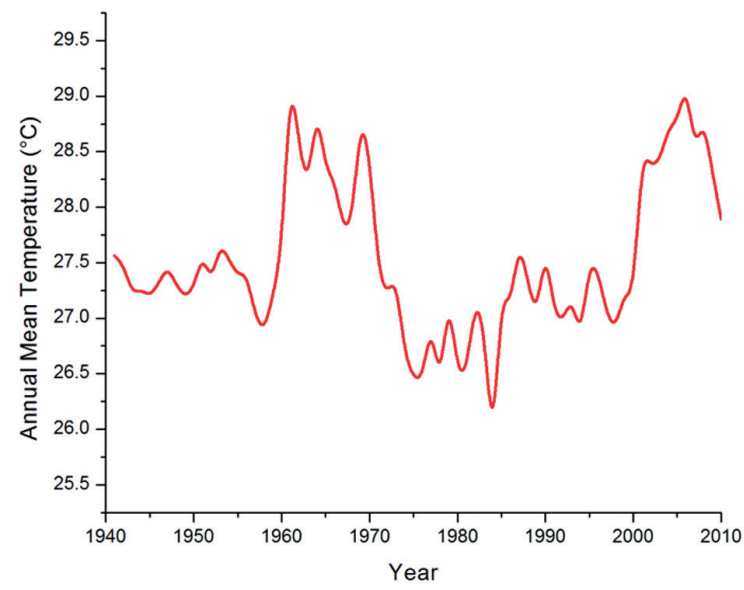

Fig. 1. Variation and trend of Annual Mean Temperature in ${ }^{\circ} \mathrm{C}$

Kolkata belongs to the tropical monsoon type of climate where the four seasons are distinct. The IMD (Indian Meteorological Department) has designated the seasons are winter (January-February), summer or pre-monsoon (March-May), monsoon or rainy (June-September) and post-monsoon or autumn (October-December). Mean monthly temperature data for the considered period has also been analysed season-wise. Temperature trends for seasonal segments fluctuate greatly; these are shown in fig. 2. The average mean seasonal temperature is at its maximum in monsoon season $\left(30.17^{\circ} \mathrm{C}\right)$ and at its minimum in the winter season $\left(22.94^{\circ} \mathrm{C}\right)$. A comparison of the four seasons reveals that mean monthly temperature is highly variable during monsoon season. The values of Sen's slope estimator for the months of January (-0.065) and February (-0.062) signify a high magnitude negative change in monthly average temperature.

The trend of mean monthly temperature for each of the months from January to December has been analysed over 70 years using the non-parametric Mann-Kendall test, along with Sen's slope estimators (table 1 and fig. 3). The Mann-Kendall tests describes the trend of the series for each of the 12 months from January to December; calculated values of the statistic are $-4.47,-6.35,-0.09,3.28$, $3.54,3.02,5.95,2.66,2.16,4.12,4.94$ and -4.91, respectively. For January, February, March and December there is evidence of a negative or decreasing trend, while the test values indicate positive trends for April, May, June, August, September, October and November. Thus, test values for four months show a negative trend and for the other eight months they show a positive trend. The months of December, January and February exhibit a highly decreasing trend, at $\alpha=0.001$ level of significance, while the month of March indicates a negative trend, though not significant one. The $Z_{c}$ value for the months of May, July, October and November indicate a positive trend, at $\alpha=$ 0.001 level of significance, while April, June and August exhibit positive trends at $\alpha=0.01$ level of significance.
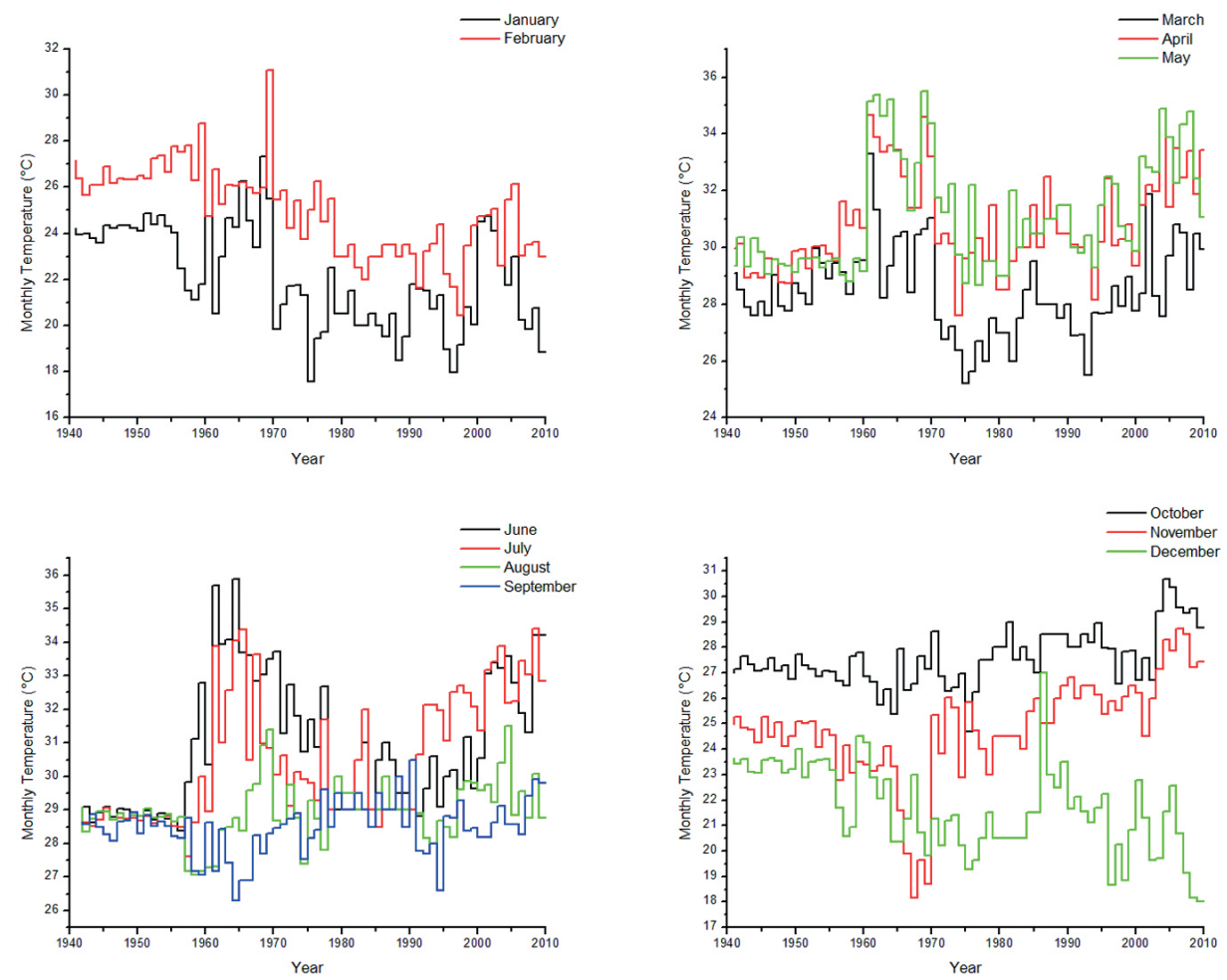

Fig. 2. Trends in Seasonal Mean Temperature (a) winter season (January-February), (b) pre-monsoon season (March-May), (c) southwest monsoon season (June-September) and (d) post-monsoon season (October-December) 
Table 1. Trend of mean monthly temperature for each of the months analysed over the 70 years using non-parametric Mann-Kendall test along with the Sen's slope estimators

\begin{tabular}{|l|c|c|c|c|}
\hline \multirow{2}{*}{$\begin{array}{l}\text { Time } \\
\text { Series }\end{array}$} & \multicolumn{3}{|c|}{ Trend in Monthly Temperature $\left({ }^{\circ} \mathrm{C}\right)$} & \multirow{2}{*}{$\begin{array}{c}\text { Significance } \\
\text { level }\end{array}$} \\
\cline { 2 - 4 } Jann-Kendall & $\begin{array}{c}\text { Sen's slope } \\
\left(Q_{i}\right)\end{array}$ & $*$ test $\left(Z_{c}\right)$ & $* * *$ \\
\hline January & 70 & -4.39 & -0.065 & $* * *$ \\
\hline Mebruary & 70 & -6.35 & -0.062 & - \\
\hline April & 70 & -0.09 & -0.001 & $* *$ \\
\hline May & 70 & 3.28 & 0.027 & $* * *$ \\
\hline June & 70 & 3.54 & 0.034 & $* *$ \\
\hline July & 70 & 5.95 & 0.061 & $* * *$ \\
\hline August & 70 & 2.66 & 0.011 & $* *$ \\
\hline September & 70 & 2.16 & 0.009 & $*$ \\
\hline October & 70 & 4.12 & 0.025 & $* * *$ \\
\hline November & 70 & 4.94 & 0.045 & $* * *$ \\
\hline December & 70 & -4.91 & -0.048 & $* * *$ \\
\hline
\end{tabular}

Note: ***Significant at 0.001 level, $* *$ Significant at 0.01 level and *Significant at 0.1 level

The estimated Sen's slope calculated for January to December indicated the magnitude of slope. However, the month of January, February, March and December indicated a decreasing or negative slope, while the rest of the months have a positive magnitude of slope. The results of trend analysis of average mean monthly temperature time series by the Mann-Kendall test and Sen's slope estimator support each other in this context.

This increase in temperature is attributed to the emission of greenhouse gases, especially $\mathrm{CO}_{2}$, from the different motor vehicles used in the city. The rough terrain of the city - it is an area that is shaped by ridges, the depressions and dissecting urban geometry, leads to only the partial combustion of the fuel which, in turn, leads to

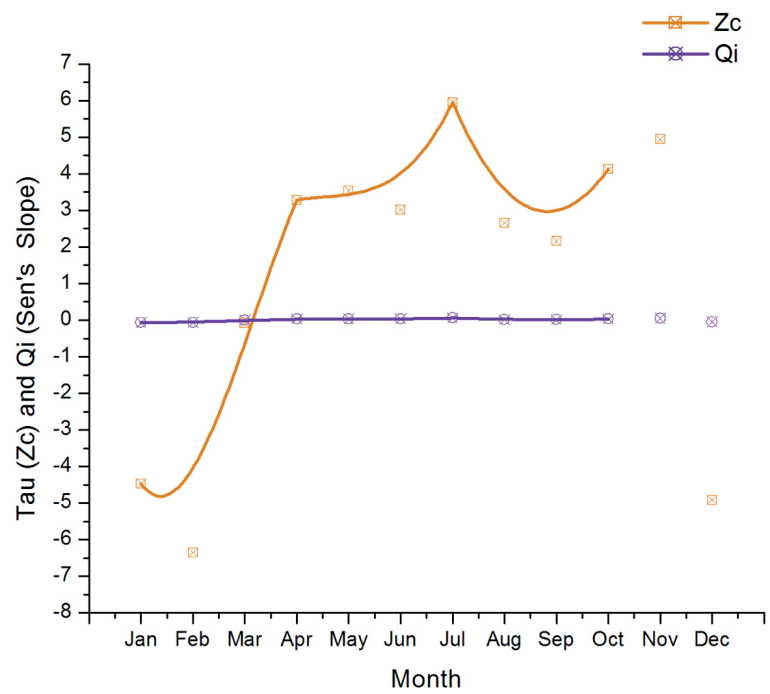

Fig. 3. Trend for individual months by Mann-Kendall test and Sen's slope an increase in the effort of engines. The factories situated around the city, as well the increase in human activities and the dearth of green areas and parks in the city; also contribute to its warming. Moreover, the Hoogly River, which surrounds the city, acts like a natural wind shield preventing the smooth circulation of air - this leads to a fluctuation in the changes in temperature of the city.

\section{Conclusion}

The application of this trend analysis framework revealed an overall increasing and decreasing trend with different levels of significance. Analysis of monthly and seasonal temperatures reveals a warming trend for the annual series and all seasonal series. The warming trend for the summer and winter seasons is statistically significant at $p<0.01$ level, with a rate of increase of $0.034^{\circ} \mathrm{C} /$ year, and $0.032^{\circ} \mathrm{C} /$ year, respectively. The considered weather observatory is in an urban area, and this region is rapidly growing. Any change in the temperature trend pattern may have considerable impact upon human life and urbanisation in this region. Therefore, it can be concluded that there may be an impact of climate variability in present times that will contribute to the prolonged and heavy temperature increase over time.

Acknowledgments. The authors would like to thank the India Meteorological Department (IMD) in Kolkata for providing climatological temperature time series for this research. The authors also thank the anonymous reviewers for their valuable and constructive suggestions.

\section{Bibliography}

Adger W.N., Aggarwal P., Agrawala S., Alcamo J., 2007, Summary for policy-makers, [in:] Climate Change 2007: Impacts, Adaptation and Vulnerability, M. Parry, O. Canziani, J. Palutikof, P. van der Linden, C. Hanson (eds.), Cambridge University Press, Cambridge, 7-22

Alexandersson H., 1984, A homogeneity test based on ratios and applied to precipitation series, Meteorologiska Institutionen, Kungl. Universitetet, Uppsala

Alexandersson H., 1986, A homogeneity test applied to precipitation data, Journal of Climatology, 6 (6), 661-675, DOI: 10.1002/joc.3370060607

Alexandersson H., Moberg A., 1997, Homogenization of Swedish temperature data. Part I: Homogeneity test for linear trends, International Journal of Climatology, 17 (1), 25-34, DOI: 10.1002/(SICI)1097-0088(199701)17:1<25::AID-JOC 103>3.0.CO;2-J 
Alexandersson J., Maier E., Reithinger N., 1995, A robust and efficient three-layered dialogue component for a speech-tospeech translation system, [in:] Proceedings of the $7^{\text {th }}$ Conference on European Chapter of the Association for Computational Linguistics, Morgan Kaufmann Publishers Inc., 188-193

Anderson R.L., 1942, Distribution of the serial correlation coefficient, The Annals of Mathematical Statistics, 13 (1), 1-13, DOI:10.1214/aoms/1177731638

Arora M., Goel N.K., Singh P., 2005, Evaluation of temperature trends over India, Water and Energy Abstracts, 15 (2), 21-21

Casa A. de la, Nasello O., 2010, Breakpoints in annual rainfall trends in Córdoba, Argentina, Atmospheric Research, 95 (4), 419-427, DOI:10.1016/j.atmosres.2009.11.005

Dash S.K., Jenamani R.K., Kalsi S.R., Panda S.K., 2007, Some evidence of climate change in twentieth-century India, Climatic Change, 85 (3-4), 299-321, DOI: 10.1007/s10584-0079305-9

Gilbert R.O., 1987, Statistical Methods for Environmental Pollution Monitoring, John Wiley \& Sons, New York, USA, 334 pp.

Hamed K.H., Rao A.R., 1998, A modified Mann-Kendall trend test for autocorrelated data, Journal of Hydrology, 204 (1), 182-196

Hawkins D.M., 1977, Testing a sequence of observations for a shift in location, Journal of the American Statistical Association, 72 (357), 180-186, DOI: 10.2307/2286934

Hingane L.S., Rupa Kumar K., Ramana Murty B.V., 1985, Long $\square$ term trends of surface air temperature in India, Journal of Climatology, 5 (5), 521-528

Hollander M., Wolfe D.A., 1973, Nonparametric statistical methods, John Wiley \& Sons Inc., 1074 pp.

IPCC, 2007, Climate change 2007 - the physical science basis, Working Group I Contribution to the Fourth Assessment report of the IPCC, (Vol. 4), Cambridge University Press

Jagannathan P., Parthasarathy B., 1973, Trends and periodicities of rainfall over India, Monthly Weather Review, 101 (4), 371-375, DOI: 10.1175/1520-0493(1973)101<0371:TAPOR $\mathrm{O}>2.3 . \mathrm{CO} ; 2$

Kendall M.G., Stuart A., 1968, Analysis of variance in the linear mode, The advanced theory of statistics, 3, 1-56
Kothawale D.R., Rupa Kumar K., 2005, On the recent changes in surface temperature trends over India, Geophysical Research Letters, 32 (18), L18714, DOI: 10.1029/2005GL023528

Pant G.B., Rupa Kumar K. (eds.), 1997, Climates of South Asia, John Wiley \& Sons Inc., Chichester, 320 pp.

Pramanik S.K., Jagannathan P., 1953, Climatic changes in India. (I)-Rainfall, Indian Journal of Meteorology and Geophysics, 4, 291-309

Salas J.D., Delleur J.W., Yevjevich V., Lane W.L., 1980, Applied modeling of hydrologic time series, Water Resources Publication, Littleton, Colorado, USA, 484 pp.

Sarker R.P., Thapliyal V., 1988, Climate change and variability, Mausam, 39, 127-138

Sen P.K., 1968, Estimates of the regression coefficient based on Kendall's tau, Journal of the American Statistical Association, 63 (324), 1379-1389, DOI: 10.1080/01621459. 1968.10480934

Shifteh Some'e B., Ezani A., Tabari H., 2012, Spatiotemporal trends and change point of precipitation in Iran, Atmospheric Research, 113, 1-12, DOI: 10.1016/j.atmosres.2012.04.016

Sinha Ray K.C., De U.S., 2003, Climate change in India as evidenced from instrumental records, Bulletin of the WMO, 52 (1), 53-58

Srivastava H.N., Dewan B.N., Dikshit S.K., Prakash Rao G.S., Singh S.S., Rao K.R., 1992, Decadal trends in climate over India, Mausam, 43 (1), 7-20

Storch H. von, Navarra A. (eds.), 1995, Analysis of Climate Variability, Springer-Verlag, Berlin, Heidelberg GmbH, 334 pp.

Tabari H., Somee B.S., Zadeh M.R., 2011, Testing for long-term trends in climatic variables in Iran, Atmospheric Research, 100 (1), 132-140

Xu Z., Liu Z., Fu G., Chen Y., 2010,Trends of major hydroclimatic variables in the Tarim River basin during the past 50 years, Journal of Arid Environments, 74 (2), 256-267, DOI: 10.1016/j.jaridenv.2009.08.014

Yue S., Pilon P., Phinney B.O.B., 2003, Canadian streamflow trend detection: impacts of serial and cross-correlation, Hydrological Sciences Journal, 48 (1), 51-63, DOI: 10.1623/ hysj.48.1.51.43478 